\title{
Uptake of Statin Guidelines to Prevent and Treat Cardiovascular Disease
}

\author{
Sebastian T. Tong, MD, MPH, Roy T. Sabo, PhD, Camille J. Hochbeimer, PhD, \\ E. Marshall Brooks, PhD, Vivian Jiang, MD, Alison N. Huffstetler, MD, \\ Paulette Lail Kashiri, MPH, and Alex H. Krist, MD, MPH
}

Introduction: In December 2013, cholesterol treatment guidelines changed the approach to statin therapy by recommending fixed doses of low-, medium-, or high-intensity statins based on cardiovascular risk. We sought to evaluate the guideline's adoption in a diverse group of practices.

Methods: Using a mixed-methods approach, we analyzed electronic health record data the year before and 2 years following guideline publication in 45 practices across 8 states. We examined associations based on patient, clinician, and practice characteristics and interviewed 24 clinicians and practice leaders to inform findings.

Results: The proportion of patients adherent with all recommendations 2 years after the guideline only increased from $18.5 \%$ to $20.3 \%(P<.01)$. There were clinically insignificant increases in statin use across risk strata (1.7\% to $3.5 \%)$ and small increases in high-intensity statin use $(2.6 \%$ to $4.6 \%)$. Only half of patients with cardiovascular disease (52.9\%) were on any statin, not much different from patients at moderate $(49.6 \%$ to $50.9 \%)$ or low (41.6\% to $48.7 \%)$ risk. Multiple patient (risk, use of health care), clinician (age), and practice (type, rurality) factors were associated with statin use. Clinicians reported patient resistance to statins but liked having a risk calculator to guide discussions.

Conclusion: Despite general agreement with statin benefit, the guideline was poorly implemented. Marginal differences in statin use between the highest and lower risk strata of patients is concerning. Rather than intensifying statin potency and recommending more patients take statins, guidelines may want to focus on ensuring that those who will benefit most get treatment. ( $\mathrm{J}$ Am Board Fam Med 2021;34:113-122.)

Keywords: Cardiovascular Diseases, Chemoprevention, Implementation Science, Statins

\section{Introduction}

Cardiovascular disease (CVD) is the leading cause of mortality in the United States. ${ }^{1}$ Medication treatment with statins reduce total and low-density lipoprotein (LDL) levels, risk of all-cause and CVD mortality and risk of CVD events. ${ }^{2}$ In December

Submitted 16 June 2020; revised 3 September 2020; accepted 8 September 2020.

From the Agency for Healthcare Research and Quality, Rockville, MD (STT); Virginia Commonwealth University, Richmond, VA (RTS, EMB, ANH, PLL, AHK); University of Virginia, Charlottesville, VA (CJH); University of Colorado, Boulder, $\mathrm{CO}(\mathrm{VJ})$.

Funding: Agency for Healthcare Research and Quality (R03HS025032), National Cancer Institute (R01CA168795), National Center for Advancing Translational Sciences (UL1TR002649).

Conflict of interest: STT is an employee of the Agency for Healthcare Research and Quality. He contributed to this article in his personal capacity. The opinions expressed are the author's own and do not reflect the view of the Agency for Healthcare Research and Quality, the Department of Health and Human Services or the Federal government.
2013, the American College of Cardiology/ American Heart Association (ACC/AHA) dramatically changed its approach to cholesterol. Since most studies randomized groups of patients at risk for CVD to take a statin or not, or to take different intensities of statins, the ACC/AHA recommended assessing the patient's CVD risk and then using a fixed dose of either a moderate- or high-intensity statin based on risk (Table 1). ${ }^{4}$ This was a fundamental change from prior guidelines that recommended using the LDL level to decide when to

AHK is the chair of the U.S. Preventive Services Task Force (USPSTF) and helped to make the USPSTF's statin preventive medication guidelines. This article represents the opinions of the authors and does not necessarily represent the views and policies of the USPSTF.

Corresponding author: Sebastian T. Tong, MD, MPH, Agency for Healthcare Research and Quality, 5600 Fishers Lane, 7th Floor Rockville, MD 20857 (E-mail: sebastian.tc. tong@gmail.com). 
Table 1. Key Recommendations from the 2013 American College of Cardiology/American Heart Association Guideline on Cholesterol Treatment

\begin{tabular}{ccc}
\hline $\begin{array}{l}\text { Risk } \\
\text { Strata }\end{array}$ & Clinical Characteristics & $\begin{array}{c}\text { Recommended } \\
\text { Statin Intensity }\end{array}$ \\
\hline $\begin{array}{c}\text { Highest } \\
\text { risk }\end{array}$ & CVD with age $\leq 75$ years & High \\
$\begin{array}{c}\text { Moderate } \\
\text { risk }\end{array}$ & LDL with age $>75$ years & Moderate \\
& Diabetes mellitus, age 40-75 & High \\
& years and estimated 10-year & High \\
& CVD risk $\geq 7.5 \%$ & \\
& Estimated 10 -year CVD & Moderate or \\
risk $\geq 10 \%$ and age 40 to 75 & high \\
& years & Moderate \\
Lower & Diabetes mellitus, age 40 to 75 \\
risk & years and estimated 10-year & \\
& CVD risk $<7.5 \%$ & Moderate or \\
& Estimated 10 -year CVD risk & high \\
& $7.5 \%$ to $10 \%$ and age 40 to 75 & \\
\hline
\end{tabular}

CVD, cardiovascular disease; LDL, low-density lipoprotein.

start a statin and to titrate the dose to achieve a target LDL level. ${ }^{5}$ Subsequent guidelines from the European $^{6,7}$ and US Preventive Services Task Force (USPSTF) ${ }^{8,9}$ took a similar risk based approach, but recommended higher CVD risk thresholds before starting statins and had less emphasis on high-intensity statins. Despite differences in risk thresholds and dosing, there is general agreement on using CVD risk to guide decisions. ${ }^{3}$

As a result of the shift in the ACC/AHA's approach, an additional 12.8 million people in the United States were estimated to be eligible for statin therapy compared with prior guidelines. ${ }^{10}$ However, several studies have shown poor uptake of the 2013 ACC/AHA guideline. These studies predominantly assessed guideline uptake 1-year postguideline release, were conducted in cardiology practices or in a limited number of health care settings and focused on generally 1 risk category of patients eligible for statin treatment. ${ }^{11-15}$ They generally found that only half to two thirds of patients received the recommended intensity statin. One study, which examined clinicians' understanding of the new guidelines using a questionnaire, found that the majority of clinicians were unable to list the 4 statin risk categories. ${ }^{16}$ Another study used the National Health and Nutrition Examination Survey data to estimate the number of Americans eligible for a statin and the Medical Expenditure Panel Survey to estimate the number of statin prescriptions to find only $40 \%$ of those eligible may be taking a statin. ${ }^{17}$ In 2018, the ACC/AHA updated its cholesterol treatment guideline, adding further complexity to the 2013 guideline's 4 statin risk categories by once again recommending the consideration of LDL levels and the use of further adjuncts to statin therapy in certain scenarios. ${ }^{18}$ This introduces the risk of further nonadherence with the guideline recommendations.

We sought to examine the patient, clinician and practice factors that influenced the uptake of the ACC/AHA guidelines across the high-, moderate-, and lowest-risk strata of patients across a diverse and representative sample of primary care practices. Our aim is to determine in which ways primary care clinicians could be assisted in ensuring the patients who could benefit most from statin therapy receive them.

\section{Methods}

Using a mixed-methods approach, we first completed a secondary data analysis of electronic health record (EHR) data from primary care practices to assess implementation of the 2013 ACC/AHA cholesterol treatment guideline. We then interviewed 15 clinicians and 9 practice leaders about their experiences implementing changes in clinical practice guidelines. This study was approved by the Virginia Commonwealth University Institutional Review Board (HM 20005306).

\section{Setting}

Forty-five practices across 8 states from 3 diverse health organizations participated in this study. These practices were recruited because they were members of 2 practice-based research networks. Twelve practices served primarily well educated, more affluent, commercially insured patients, 9 served an urban safety-net health system that cared for high numbers of black patients, and 24 belonged to a network of community health centers. Each of the 3 organizations had 1 residency/student training practice.

\section{Outcomes}

We examined 1) whether the patient was prescribed a statin, and 2) intensity of the statin as a function of the 2013 ACC/AHA patient risk strata (Table 1) for the year before guideline publication (hereafter referred to as baseline) and each of 2 years following guideline publication. For each risk strata, we calculated any 
statin use and use of the recommended statin based on intensity. We further examined use of nonstatin medication, which was recommended against in the guideline and the proportion of patients with annual lipid panel testing, which may not be necessary for patients at low risk (who are unlikely to change risk category in 1 year) and for patients currently using the recommended statin medication.

\section{Data Collection}

Informatics staff for each health system queried EHR data for patients aged 18 to 89 years with visit encounters at any of the participating clinics between 2012 and 2016. The data included demographics, all active diagnoses, dates and diagnoses made for each visit, vital signs for each visit, and all laboratory results and prescriptions for the time period. We then linked patients to their primary care clinicians, and using existing network databases that described the practice and clinician characteristics, ${ }^{19}$ we cross matched results to clinician, practice, and health system characteristics. If a patient had more than 1 visit for a given year, we used the last visit for that year. CVD risk for patients was calculated using the Pooled Cohort Risk Assessment Equations recommended by the ACC/AHA. ${ }^{4}$

Semistructured interviews were conducted with 15 clinicians and 9 practice leaders from 15 representative practices in Montana, North Carolina, Ohio, Oregon, and Virginia. Interviewees were purposefully sampled from clinicians and practice leaders at clinics participating in the study to represent a range in years of practice, gender, ethnicity/ race, and practice setting (eg, rural/urban, private/ safety-net, etc.). From an interview guide, we asked questions about how interviewees stayed up to date with guideline changes and what patient, clinician, practice, health system, environmental and guideline-specific factors they felt influenced uptake of guidelines. The interviews, which lasted between 30 and 60 minutes, were conducted over the phone, audio recorded, and transcribed.

\section{Statistical Analysis}

We calculated counts and frequencies of patients that fit into each of the listed categories for the index year as well as each of the 2 years following that change. Generalized linear mixed models were used to test for trends over time, where a binary indicator of whether a patient received the appropriate intensity statin or any statin was prescribed was included as a binary outcome against a 3-level time effect (baseline year, year 1 and year 2.) Dependence over time within patients was modeled using a compound symmetric correlation structure; clinician and practice were intended to be included as random effects, but the resulting models did not converge, and thus those terms were not included. Associations between statin use and patient, clinician and practice characteristics were also investigated using generalized linear mixed models, focusing solely on year- 2 data. The patient-level analyses included binary outcomes indicating whether patients were on a statin, patient characteristics were jointly included as fixed effects, and clinician and practice variability was accounted for through random effects. The clinician-level analyses included binomial outcomes of the number of patients on statins divided by the number of patients for that clinician, clinician characteristics were jointly included as fixed effects, and practice-level variability was accounted for as a fixed effect. The practice-level analyses included binomial outcomes of the number of patients on statins divided by the number of patients for that practice, while practice characteristics were included as fixed effects in separate models due to small sample size. Associations were summarized with odds ratios and 95\% CIs for each characteristic. The FREQ and GLIMMIX procedures of the SAS statistical software (version 9.4; SAS Institute Cary, NC) were used.

\section{Qualitative Data Analysis}

We analyzed transcribed data using a combination of techniques for coding qualitative data, including template and emergent coding processes in the software package Atlas version 7 (Atlas.ti, Berlin, Germany). ${ }^{20}$ Template-based codes were derived from topics in the interview guide in an iterative process. An initial code was used to begin organization of transcripts and during development, the code was restructured; emergent themes were identified during analysis and incorporated into the codebook. Six codes were developed, and 12 dominant themes emerged; these were the foundation for review of data. Authors $\mathrm{EMB}, \mathrm{VJ}$, and $\mathrm{AK}$, who were blinded to who was being interviewed and their statin prescribing, independently reviewed the transcripts, then met to resolve discrepancies and achieve consensus on themes and findings. 
Table 2. Characteristics of Patients Included in Study to Examine Uptake of AHA/ACC Cholesterol Treatment Guidelines $(\mathrm{n}=\mathbf{2 2 3}, \mathbf{2 8 9})$

\begin{tabular}{|c|c|}
\hline Characteristics & $\mathrm{n}(\%)$ \\
\hline \multicolumn{2}{|l|}{ Gender } \\
\hline Male & $9,9569(44.6 \%)$ \\
\hline Female & $12,3707(55.4 \%)$ \\
\hline \multicolumn{2}{|l|}{ Ethnicity } \\
\hline Hispanic & $1,1354(5.8 \%)$ \\
\hline Non-Hispanic & $18,4724(94.2 \%)$ \\
\hline \multicolumn{2}{|l|}{ Race } \\
\hline Asian & $1,6613(8.2 \%)$ \\
\hline Black & $2,9500(14.5 \%)$ \\
\hline Other & $1,4842(7.3 \%)$ \\
\hline White & $14,2230(70.0 \%)$ \\
\hline \multicolumn{2}{|l|}{ Insurance Type } \\
\hline Commercial & $16,8692(75.7 \%)$ \\
\hline Medicaid & $1,2361(5.5 \%)$ \\
\hline Medicare & $2,8217(12.7 \%)$ \\
\hline Uninsured & $1,3655(6.1 \%)$ \\
\hline Average age in years (SD) & $53.3(9.9)$ \\
\hline \multicolumn{2}{|l|}{ Age, years } \\
\hline 18 to 30 & $473(0.2 \%)$ \\
\hline 31 to 39 & $2580(1.1 \%)$ \\
\hline 40 to 49 & $8,6519(38.8 \%)$ \\
\hline 50 to 59 & $7,4710(33.5 \%)$ \\
\hline 60 to 69 & $4,3678(19.6 \%)$ \\
\hline 70 to 79 & $1,3475(6.0 \%)$ \\
\hline$\geq 80$ & $1854(0.8 \%)$ \\
\hline
\end{tabular}

AHA, American Heart Association; ACC, American College of Cardiology; SD, standard deviation.

\section{Results}

A total of 223,289 patients were included, of which $55.4 \%$ were female, $5.8 \%$ Hispanic, $14.5 \%$ black, and the average age was 53.3 years (Table 2).

\section{Guideline Uptake}

The overall percentage of patients who are receiving treatment in accordance with the 2013 cholesterol guidelines increased marginally from $18.5 \%$ at baseline to $20.3 \%$ in year $2(P<.01)$ (Table 3$)$. For patients with CVD, there was a slight increase in use of high intensity statins $(16.4 \%$ to $20.5 \%, P<.01)$, but no increase in use of any statin $(52.5 \%$ to $52.9 \%$, $P=.73)$. For moderate-risk patients, patients with LDL $\geq 190$ had no increases in high-intensity or any statin use; patients with diabetes and a risk $\geq 7.5 \%$ had small increases in high-intensity $(12.2 \%$ to $15.1 \%, P<.01)$ and any statin use $(54.7 \%$ to $56.6 \%$, $P=.05$ ); and any patient with a risk $\geq 10 \%$ also had increases in high-intensity ( $43.0 \%$ to $45.6 \%, P<.01$ ) and any statin use $(47.9 \%$ to $49.6 \%, P<.01)$. For lower-risk patients, there was an increase in high-intensity $(40.8 \%$ to $44.9 \%, P<.01)$ and any statin $(45.2 \%$ to $48.7 \%, 0<0.01)$ for patients with diabetes and risk $<7.5 \%$, but no change in all patients with a risk of $7.5 \%$ to $10 \%$.

\section{Overuse and Non-Recommended Care}

Despite recommendations against nonstatins, use of drugs such as niacin, bile acid sequestrates, fibrates, and ezetimibe increased similar amounts as statin use (10.7\% to $11.3 \%, P<.01)$. Similarly, annual lipid measurement, which is unnecessary for patients taking the recommended statin doses, increased $(62.8 \%$ to $65.9 \%, P<.01)$.

\section{Associations with Patient, Clinician, and Practice Characteristics}

As patients' risk increased-being male, increased age, increased comorbidity - there was consistently greater likelihood of statin use across risk strata (Table 4). Similar increases across risk strata were seen for patients with greater contact with health care-a recent wellness visit or more overall visits. There were no consistent changes based on race or ethnicity. However, patients with Medicaid were generally less likely to be on a high-intensity statin. Attending clinicians consistently had more patients using any statin and high-intensity statins than residents. Clinicians over 50 years were generally less likely to prescribe high-intensity statins, except in primary prevention, or treat patients with diabetes with a statin, but were more likely to treat patients with CVD and for primary prevention with any statin. Community health centers and private practices had fewer patients using high-intensity and any statin across risk strata than university-affiliated practices. Rural and suburban practices also were less likely to have patients using high-intensity and any statin across risk strata compared with urban practices. Practices that implemented systems to promote evidence-based care, such as longer EHR use, longer patient portal use, and standing orders for lipid measurement and statin prescribing, had substantially more patients use high-intensity and any statin.

\section{Clinician and Practice Leader Perspectives}

Multiple themes emerged from interviews with clinicians and practice leaders (Table 5). In terms of patient factors, interviewees noted that some patients 
Table 3. Uptake of Statin Use for Prevention of Cardiovascular Disease Guideline Using Electronic Health Record Patient Data from 2013-2016

\begin{tabular}{|c|c|c|c|c|}
\hline Category & Baseline & 1 Year After & 2 Years After & $P$-Value \\
\hline \multicolumn{5}{|l|}{ Overall guideline uptake } \\
\hline $\begin{array}{l}\text { Overall uptake of } 2013 \text { ACC/ } \\
\text { AHA guideline }\end{array}$ & $18,690(18.5 \%)$ & $20,408(19.0 \%)$ & $21,719(20.3 \%)$ & $<.01$ \\
\hline \multicolumn{5}{|l|}{ Highest-risk patients-CVD } \\
\hline $\begin{array}{l}\text { Age } 40 \text { to } 75 \text { years with CVD } \\
\text { on high-dose statin }\end{array}$ & $1435(16.4 \%)$ & $1764(18.1 \%)$ & $2227(20.5 \%)$ & $<.01$ \\
\hline $\begin{array}{l}\text { Age } 40 \text { to } 75 \text { years with CVD } \\
\text { on any statin }\end{array}$ & $4592(52.5 \%)$ & $5101(52.4 \%)$ & $5757(52.9 \%)$ & .73 \\
\hline \multicolumn{5}{|c|}{ Moderate-risk patients-heredity hyperlipidemia or diabetes (risk $\geq 7.5 \%$ ) or primary prevention (risk $\geq 10 \%$ ) } \\
\hline $\begin{array}{l}\text { Age } 40 \text { to } 75 \text { years with } \\
\text { LDL } \geq 190 \text { on high-dose } \\
\text { statin }\end{array}$ & $124(10.8 \%)$ & $160(12.7 \%)$ & $158(12.8 \%)$ & .26 \\
\hline $\begin{array}{l}\text { Age } 40 \text { to } 75 \text { years with } \\
\text { LDL } \geq 190 \text { on any statin }\end{array}$ & $592(51.8 \%)$ & $638(50.6 \%)$ & $626(50.9 \%)$ & .85 \\
\hline $\begin{array}{l}\text { Age } 40 \text { to } 75 \text { years with DM } \\
\text { and } \geq 7.5 \% \text { risk on high- } \\
\text { dose statin }\end{array}$ & $904(12.2 \%)$ & $1124(13.8 \%)$ & $1353(15.1 \%)$ & $<.01$ \\
\hline $\begin{array}{l}\text { Age } 40 \text { to } 75 \text { years with DM } \\
\text { and } \geq 7.5 \% \text { risk on any } \\
\text { statin }\end{array}$ & $4044(54.7 \%)$ & $4513(55.3 \%)$ & $5067(56.6 \%)$ & .05 \\
\hline $\begin{array}{l}\text { Age } 40 \text { to } 75 \text { years } \\
\text { with }>10 \% \text { risk on } \\
\text { moderate- or high-dose } \\
\text { statin }\end{array}$ & $6046(43.0 \%)$ & $6704(43.6 \%)$ & $7541(45.6 \%)$ & $<.01$ \\
\hline $\begin{array}{l}\text { Age } 40 \text { to } 75 \text { years } \\
\text { with }>10 \% \text { risk on any } \\
\text { statin }\end{array}$ & $6733(47.9 \%)$ & $7413(48.2 \%)$ & $8216(49.6 \%)$ & $<.01$ \\
\hline \multicolumn{5}{|c|}{ Lower-risk patients-diabetes or primary prevention and risk $<7.5 \%$} \\
\hline $\begin{array}{l}\text { Age } 40 \text { to } 75 \text { years with DM } \\
\text { and }<7.5 \% \text { risk on } \\
\text { moderate- or high-dose } \\
\text { statin }\end{array}$ & $2879(40.8 \%)$ & $3323(43.3 \%)$ & $3647(44.9 \%)$ & $<.01$ \\
\hline $\begin{array}{l}\text { Age } 40 \text { to } 75 \text { years with DM } \\
\text { and }<7.5 \% \text { risk on any } \\
\text { statin }\end{array}$ & $3192(45.2 \%)$ & $3664(47.7 \%)$ & $3957(48.7 \%)$ & $<.01$ \\
\hline $\begin{array}{l}\text { Age } 40 \text { to } 75 \text { years with } 7.5 \text { to } \\
10 \% \text { risk on moderate- or } \\
\text { high-dose statin }\end{array}$ & $1211(37.9 \%)$ & $1315(37.9 \%)$ & $1363(37.7 \%)$ & .99 \\
\hline $\begin{array}{l}\text { Age } 40 \text { to } 75 \text { years with } 7.5 \text { to } \\
10 \% \text { CVD risk on any statin }\end{array}$ & $1325(41.5 \%)$ & $1441(41.5 \%)$ & $1504(41.6 \%)$ & .99 \\
\hline \multicolumn{5}{|c|}{ Patients receiving non-recommended care or potential overuse } \\
\hline $\begin{array}{l}\text { Age } 40 \text { to } 75 \text { years on non- } \\
\text { statin medication }\end{array}$ & $10,454(10.7 \%)$ & $11,282(10.9 \%)$ & $11,642(11.3 \%)$ & $<.01$ \\
\hline $\begin{array}{l}\text { Age } 40 \text { to } 75 \text { years on } 80-\mathrm{mg} \\
\text { simvastatin* }^{*}\end{array}$ & $541(0.6 \%)$ & $460(0.4 \%)$ & $455(0.4 \%)$ & $<.01$ \\
\hline $\begin{array}{l}\text { Any age on a statin without } \\
\text { an indication }\end{array}$ & $1867(7.0 \%)$ & $1919(6.6 \%)$ & $1890(6.2 \%)$ & $<.01$ \\
\hline $\begin{array}{l}\text { Age } 40 \text { to } 75 \text { years with lipid } \\
\text { measurement in past } \\
15 \text { months }\end{array}$ & $61,350(62.8 \%)$ & $66,468(64.2 \%)$ & $67,974(65.9 \%)$ & $<.01$ \\
\hline
\end{tabular}

ACC, American College of Cardiology; AHA, American Heart Association; CVD, cardiovascular disease; DM, diabetes mellitus; LDL, low-density lipoprotein.

Italic value denotes statistically significant increase in guideline uptake compared with baseline and adjusted for clinician and practice (included as random effects).

Bold italic value denotes statistically significant decrease in guidelines uptake compared with baseline and adjusted for clinician and practice (included as random effects).

${ }^{*}$ Current FDA black box warning recommends against using simvastatin at 80-mg dosing. 


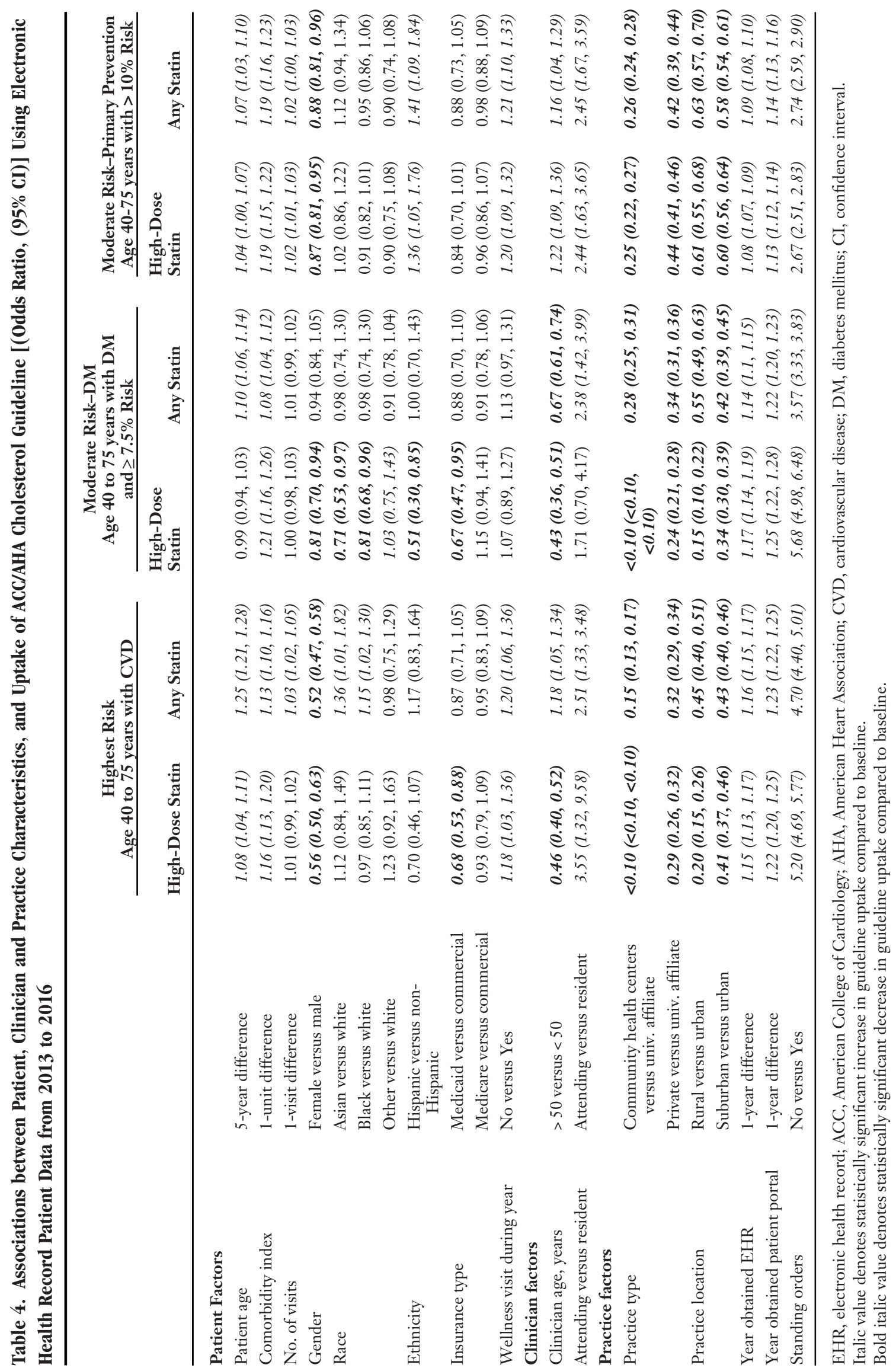

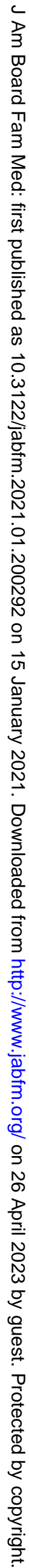


Table 5. Perspectives from Clinicians and Practice Leaders on Factors Affecting Guideline Implementation from Qualitative Interviews

Themes/Findings $\quad$ Quotations

\section{Patient factors}

Factors external to the clinic (ex. TV ads and experiences of friends and family) can affect patient attitudes.

Some patients may be initially resistant to change and need multiple visits and promptings to adjust to new guidelines.

Patient education with concrete numbers and measurements helps with guideline implementation

\section{Clinician factors}

Primary care clinicians need more time to engage patients to help with reducing frequency of or ceasing testing when they are recommended.

Although clinicians are frustrated with the frequency with which guidelines change, they are committed to making changes that are based on new evidence.

Clinicians want to engage patients in shared decisions.

\section{Practice/health system factors}

EHR templates are not always up to date with current guideline recommendations.

EHR can help facilitate care by automatically calculating CVD risks.

Quality metrics that clinicians are held accountable to are not always up to date with current guideline recommendations.

EHR, electronic health record; CVD, cardiovascular disease.

initially resistant to change may have been influenced by factors beyond the interviewees' control, such as advertisements or learning about the experiences of friends and family who take statins. However, multiple clinicians noted that having concrete numbers and the CVD risk calculator helped with patient education and decision making.

Clinicians expressed frustration with how frequent changes are made to guidelines, with 1 clinician saying, "There seems to be no end in sight to how you can flip these numbers and come up with another guideline." However, clinicians overall seemed to understand that new evidence regularly emerges and were committed to implementing the
“Quite a few folks are leery about statins. They've seen ads on TV saying there are potential side effects. 'I know my Aunt Suzi had problems and I'm not going to do that to myself."

"Some people, despite all of the evidence I show them, still don't want to do something; like starting a statin. I respect their decision. I say that's fine. I'll bring it up with you again in a year."

"I think having the risk calculators... having some numbers to discuss with people about what we think their risk is and how much the risk might be reduced if they took medicine, I think that's helpful."

"I spent 10 minutes telling a lady who had her cholesterol checked twice this year that she didn't need to check it a third time. You know how much more time it takes to tell somebody they don't need a test than to tell them, oh sure, I'll order another test. That would have taken me 5 seconds; and 10 minutes later I'm like, no you don't need to do it a third time."

"There seems to be no end in sight to how you can flip these numbers and come up with another guideline about stuff. It's nice to be up to date on that kind of thing, although I find sometimes that we do end up flipping pretty quickly on things. But that's okay. If the original thing was founded on not enough data and they got more data, then great."

"I'm a big believer in kind of the mutual decision; not just me telling them what to do, and realistically if they don't believe what I'm saying they won't do it anyway."

"The other thing we'll do sometimes is look at existing templates in the EMR and see if the templates are consistent with guidelines."

"For me to be able to type in CVD risk and have it calculate out then 10 -year risk is amazingly helpful rather than having to go on the calculator every time and enter stuff in."

"I mean we have these quality guidelines now that kind of drive me insane. They're helpful to a point. They kind of make me crazy too because I don't feel like those are as up to date as we are maybe." 


\section{Discussion}

While there were statistically significant increases in the uptake of the cholesterol treatment recommendations from baseline to 2 years post-guideline publication, these increases were marginal and were noted for non-recommended care as well as recommended care. Just over half of patients in the highest-risk category, those with CVD, were on any statin and a fifth were on the recommended highintensity statin dose. In fact, patients in the moderate-risk category of diabetes mellitus were slightly more likely than those with CVD to be on any statin. However, patients who demographically are higher risk-men and those of older age-were more likely to have be on the recommended highintensity or any statin. In addition, systems-level interventions such as EHR prompts, seemed to be associated with higher uptake of guidelines.

Poor uptake of cholesterol guidelines was also seen in community health centers and practices that care for higher proportions of patients with Medicaid insurance. Furthermore, patients with Medicaid insurance were less likely to be on highintensity statins when recommended. While the cause of discrepancies in uptake of cholesterol guidelines for patients of community health centers and with Medicaid is unknown, these disparities in ACC/AHA guideline implementation, which have been documented with implementation of other guideline changes, ${ }^{21}$ need particular attention to ensure that underserved patients do not end up with poorer health outcomes.

Our findings also suggest that clinicians are frustrated with the frequency of guideline changes. While interviews suggest that most clinicians are knowledgeable of and generally accepting of the guideline, EHR data show that the cholesterol treatment guideline remained poorly implemented. Some of the poor implementation may be caused by external factors, such as patients' reluctance to change and outdated EHR prompts and insurance quality metrics. In addition, the guidelines' multiple statin benefit categories and recommendations of different doses based on 10-year CVD risk within some of the statin benefit categories are of high complexity. This may add to the difficulty in implementing the cholesterol treatment guidelines.

Furthermore, some of the reluctance to aggressively place patients on statins may be a result of disparate guidelines that are published by other organizations. For example, in 2016, the USPSTF published cholesterol treatment guidelines that differed with the 2013 ACC/AHA guidelines. In addition, the ACC/AHA updated their 2013 guidelines with recommendations with increasing complexity in 2018 with a focus on decreasing LDL levels with more medications despite the limited evidence on improved outcomes from focusing on LDL levels. This may result in even greater confusion among clinicians and patients and further reluctance to implement guidelines that clinicians may not easily grasp or remember.

Our study adds to existing literature on uptake of clinical practice guidelines by highlighting the challenges of implementing a particularly complex guideline on treatment of high cholesterol. The time course of our study allowed clinicians and practice leaders who were interviewed to reflect on their experiences implementing this guideline over the course of 3 to 5 years. Our study results also draw attention on the need for primary care clinicians to focus their efforts in implementing complex guidelines on the patients for whom implementation would have the highest yield in health outcomes. In this case, our study results showed that patients in the highest CVD risk strata who would benefit most from statins were no more likely to be on the appropriate dose statin than patients in lower CVD risk strata. Given the poor uptake of the 2013 guidelines overall and specifically in the patients in the highest risk strata, clinical guidelines could potentially focus on recommendations that would decrease mortality and morbidity in the highest-risk patients, those with CVD, and in moderate-risk patients. Guideline developers could prioritize recommendations with strong evidence and for patients at the highest risk strata rather than creating guidelines of increasing complexity, which could result in poor implementation, and that focused on recommendations with limited evidence or marginal benefit to patients.

Several limitations exist. While the sample included a broad range of practices, they were all practices that had agreed to participate in a research study and may not represent the typical clinician and/or practice. Furthermore, clinicians and practice leaders who agreed to participate in interviews may have been more engaged and likely to implement new guidelines. In addition, an inherent limitation of using EHR data are that any care received outside of that health system may not be accounted for in the study. Another limitation is that we only 
assessed the impact of prespecified clinician, practice and patient factors discussed in the manuscript on the uptake of guidelines and other factors not assessed may have influenced uptake.

\section{Conclusion}

While primary care clinicians are knowledgeable about and generally in agreement with the 2013 ACC/AHA guideline for cholesterol treatment, the guideline has been poorly implemented, especially for traditionally underserved populations and for patients in the highest risk strata. The increasing complexity of clinical practice guidelines, especially with the recent publication of the 2018 ACC/AHA guideline, may further detract from efforts to ensure that patients in higher risk strata are prescribed statins. Primary care clinicians can best serve their patients by focusing on implementation efforts for cholesterol guidelines on recommendations that would have the highest yield for high-risk strata patients. Meanwhile, guideline developers could best decrease overall and CVD mortality and morbidity by focusing on creating evidence-based recommendations that prioritize those that would benefit most from treatment with statins.

\section{To see this article online, please go to: http://jabfm.org/content/ 34/1/113.full.}

\section{References}

1. Mensah GA, Brown DW. An overview of cardiovascular disease burden in the United States. Health Aff (Millwood) 2007;26:38-48.

2. Chou R, Dana T, Blazina I, Daeges M, Jeanne TL. Statins for prevention of cardiovascular disease in adults: evidence report and systematic review for the US Preventive Services Task Force. JAMA 2016;316:2008-24.

3. Mortensen MB, Nordestgaard BG. Statin use in primary prevention of atherosclerotic cardiovascular disease according to 5 major guidelines for sensitivity, specificity, and number needed to treat. JAMA Cardiol 2019;4:1131-8.

4. Stone NJ, Robinson J, Lichtenstein AH, et al. 2013 ACC/AHA Guideline on the treatment of blood cholesterol to reduce atherosclerotic cardiovascular risk in adults: a report of the American College of Cardiology/American Heart Association Task Force on Practice Guidelines. Circulation 2014;129:S1-S45.

5. National Cholesterol Education Program. ATP III guidelines at-a-glance: quick desk reference. 2004. Available from: https://www.nhlbi.nih.gov/files/docs/ guidelines/atglance.pdf. Accessed February 24, 2020.
6. Rabar S, Harker M, O'Flynn N, Wierzbicki AS. Lipid modification and cardiovascular risk assessment for the primary and secondary prevention of cardiovascular disease: summary of updated NICE guidance. BMJ 2014;349:g4356.

7. Ray KK, Kastelein JJP, Boekholdt SM, et al. The ACC/AHA 2013 guideline on the treatment of blood cholesterol to reduce atherosclerotic cardiovascular disease risk in adults: the good the bad and the uncertain: a comparison with ESC/EAS guidelines for the management of dyslipidaemias 2011. Eur Heart J 2014;35:960-8.

8. Bibbins-Domingo K, Grossman DC, Curry SJ, et al. Statin use for the primary prevention of cardiovascular disease in adults: US Preventive Services Task Force recommendation statement. JAMA 2016;316:1997-2007.

9. Chou R, Dana T, Blazina I, et al. Statin use for the prevention of cardiovascular disease in adults: a systematic review for the U.S. Preventive Services Task Force. Rockville, MD: Agency for Healthcare Research and Quality (US); 2016.

10. Pencina MJ, Navar-Boggan AM, D'Agostino Sr $\mathrm{RB}$, et al. Application of new cholesterol guidelines to a population-based sample. $\mathrm{N}$ Engl J Med 2014;370:1422-31.

11. Pokharel Y, Tang F, Jones PG, et al. Adoption of the 2013 American College of Cardiology/American Heart Association Cholesterol Management guideline in cardiology practices nationwide. JAMA Cardiol 2017;2:361-9.

12. Bellows BK, Olsen CJ, Voelker J, Wander C. Antihyperlipidemic medication treatment patterns and statin adherence among patients with ASCVD in a managed care plan after release of the 2013 ACC/AHA guideline on the treatment of blood cholesterol. J Manag Care Spec Pharm 2016;22: 892-900.

13. Rodriguez F, Lin S, Maron DJ, Knowles JW, Virani SS, Heidenreich PA. Use of high-intensity statins for patients with atherosclerotic cardiovascular disease in the Veterans Affairs Health System: practice impact of the new cholesterol guidelines. Am Heart J 2016;182:97-102.

14. Harrison TN, Scott RD, Cheetham TC, et al. Trends in statin use 2009-2015 in a large integrated health system: pre- and post-2013 ACC/AHA guideline on treatment of blood cholesterol. Cardiovasc Drug Ther 2018;32:397-404.

15. Tran JN, Kao TC, Caglar T, et al. Impact of the 2013 cholesterol guideline on patterns of lipid-lowering treatment in patients with atherosclerotic cardiovascular disease or diabetes after 1 year. J Manag Care Spec Pharm 2016;22:901-8.

16. Virani SS, Pokharel Y, Steinberg L, et al. Provider understanding of the 2013 ACC/AHA cholesterol guideline. J Clin Lipidol 2016;10:497504.e494. 
17. Ngo-Metzger Q, Zuvekas SH, Bierman AS. Estimated impact of US Preventive Services Task Force recommendations on use and cost of statins for cardiovascular disease prevention. J Gen Intern Med 2018;33:1317-23.

18. Grundy SM, Stone NJ, Bailey AL, et al. 2018 AHA/ACC/AACVPR/AAPA/ABC/ACPM/ADA/ AGS/APhA/ASPC/NLA/PCNA guideline on the management of blood cholesterol: a report of the American College of Cardiology/American Heart Association Task Force on clinical practice guidelines. J Am Coll Cardiol 2019;73:e285-e350.
19. Krist AH, Aycock RA, Etz RS, et al. MyPreventiveCare: implementation and dissemination of an interactive preventive health record in three practice-based research networks serving disadvantaged patients-a randomized cluster trial. Implement Sci 2014;9:181.

20. Ryan GW, Bernard HR. Techniques to identify themes. Field Methods 2003;15:85-109.

21. Adler NE, Cutler DM, Fielding JE, et al. Addressing social determinants of health and health disparities: A vital direction for health and health care. NAM Perspectives. Discussion Paper, National Academy of Medicine. Washington, DC; 2016. 